\title{
Thai Students' Decision Making in Societal Issue of Surface Area and Concentrated Solutions as a Factor in the Rate of Chemical Reactions
}

\author{
Jeeruwan Chattabud \\ Paisan Suwannoi
}

Tawee Sranamkam

Chokchai Yuenyong*

\begin{abstract}
Science Education Program, Faculty of Education, Khon Kaen University, Thailand
\end{abstract}
*Corresponding Author Email: ychok@kku.ac.th

\author{
Doi:10.5901/mjss.2015.v6n6s1p56
}

\begin{abstract}
This research is aimed at clarifying how Thai students' make decisions as regards societal issues of surface area and concentrated solutions as a factor in the rate of chemical reactions. The STS unit of rate of chemical reactions had been taught to 35 Grade 11 students for four weeks in Ban Haed District of Khon Kaen Province, Thailand. The unit consists of four subunits: (i) surface area and concentrated solutions, (ii) catalysts, (iii) temperature, and (iv) inhibiter. This submission is made up of only one sub-unit, surface area and concentrated solutions. Methodology has to do with interpretive paradigm. Tools of interpretation includes i) participant observation ii) individual and group, and informal interview, iii) journal writing or personal summary, and iv) students' tasks. Students' responds, dialogues, ideas, or conversations which are being categorized in to constructed patterns in order to explain to students' the common themes of the normative decision making model. The finding revealed that students could develop the model of decision making. Their model could be classified in to six steps: i) options ii) criteria iii) classification of information in to each criterioniv) Evaluating the advantages and disadvantages of each alternative, v) choice analysis, and vi) selection of the best alternative. It indicated that students could apply the relationship between science, technology and society into their decision making process. This submission also has as a rationale, to enhance students' scientific literacy.
\end{abstract}

Keywords: STS, chemical reactions, decision making, scientific literacy

\section{Introduction}

Thailand science education provided the vision of science learning as expectation of Thai students' awareness of a lifelong learning and interplay science, technology and society. This suggested teachers to emphasize science teaching related to the world outside classroom or using everyday life situation or local information to engage students' scientific inquiry. Students have to learn science from different dimension - natural phenomena and scientific issues in society. The goal of Thai science education clearly mentioned that science learning should be generated through the relationship between science, technology and society (IPST, 2002).

Science learning through science, technology and society (STS) approach was suggested by science educators across the world for decades to making sense of science out of everyday life and for future. The STS approach also motivates students to critically learn science and apply scientific knowledge as social responsibility in collective decision making on STS issues. These issues require students or citizens who held scientific literacy (Aikenhead, 1994). In fact, there were some studies of STS approach for science teaching and learning in order to enhance scientific literacy in Thailand. They tried to reach scientific literacy by developing various skills related to STS issues including thinking skills, decision making, social responsibility, Thai core values, and perception of the relationship between science, technology and society (Yuenyong and Narjaikaew, 2009). Yuenyong (2013) reported about the research based in Thailand that focused on decision making, normative decision-making, and the process of decision-making in STS science learning. Those research applied Yuenyong (2006)'s STS approach for developing STS learning unit. Yuenyong (2006)'s STS approach consisted of five stages: (1) identification of social issues; (2) identification of potential solutions; (3) need for knowledge; (4) decision-making; and (5) socialization stage. 


\section{Literature}

\subsection{Process of Decision Making}

Engagement of science learning by linking science technology and society needs students' decision making in science learning. Decision making is seen as a process that to find solutions, values or some action on the issues. The decision making process, therefore, allows students to apply value judgments and various kinds of knowledge (Kortland, 1996, Bingle \& Gaskell, 1994; Ratcliffe, 1995). Considering process of decision making, actions of person, who will make decision, have to making of reasonable choices from various alternatives. It is leading to the formulation of a normative model for the decision making process (Kortland, 1996).

Normative decision making model will show processes of step-by-step that represent rational decision making. In general, idea of normative decision making model may include procedures that consider identifying the problem, generating criterias, developing and evaluating choices, and finally selecting and implementing the best solution (Raticliffe, 1995; Kortland, 1996). There were many framework of normative decision making model in literature review. However, they suggested the common themes of normative decision making model as following six steps (Kortland 1992, 1995, and 1996; and Raticliffe, 1995).

(i) Options: Recognize the potential choices of action concerning on the nature of problem.

(ii) Criteria: Generate or mention appropriate criteria to use for comparing the alternatives.

(iii) Validity and clarification of information of each criterion: Explain or provide the information known about potential choices with particular mention to framework and to scientific knowledge or evidence.

(iv) Evaluation or survey: Weight the advantage and disadvantages of each choice against the criteria identified or evaluate conflicting results of comparison of the different.

(v) Choice: Select a choice based on the analysis undertaken.

(vi) Review: weigh up the decision making process undertaken, mentioning and possibly improvement it.

Students' understanding of the relationship between science, technology and society is another crucial goal of science education. Enhancing students' decision making may allow students to perceive relationship between science, technology and society. The STS unit of rate of chemical reactions may give students opportunity to learn chemical reaction related to technology and society. The STS unit also provides students to make decision on chemical reactions in local issues. Next, the STS approach will be discussed.

\subsection{Science Technology and Society (STS) Approach}

Students' decision making needs many kinds of knowledge. However, scientific knowledge is an important knowledge for human activities and limitation of applying other knowledge. It seemed that students, who held perception of the relationship between science, technology and society, could gain the ability of decision making (Anantasook and Yuenyong, 2010; Yuenyong, 2012). Yuenyong (2013) reported about the research based in Thailand that focused on decision making, normative decision-making, and the process of decision-making in STS science learning. Those research applied Yuenyong (2006)'s STS approach for developing STS learning unit. Each stage of Yuenyong (2006) STS approach could be explained as follows:

(i) Identification of social issues stage: The stage is designed to gain students' attention and attitudes on learning about science. This stage will engage students through the technological and societal issues or the outside classroom issues. These issues or problems should be found solution or generated the best solutions for their society.

(ii) Identification of potential solutions stage: After identify the problem, students should have chance to plan how to solve the problems or raise the alternatives for the solutions. Scientific and other knowledge may be listed to support the issues. What the need of knowledge may also be clarified by students. The stage requires students to think of what, why, and how ideas, design, system, volition of applying scientific knowledge and others should be worked for social problems. These reflect that students need to be enhanced to construct meaning of technological concept in this stage.

(iii) Need for knowledge stage: The stage aims to develop students' scientific knowledge which need for decision making on how to do alternatives and the best solutions. Students should be provided learning activities for scientific inquiry. Scientific concepts have been formulated in many ways to help students to understand technology and social issues.

(iv) Decision-making stage: 
The stage is designed students to apply scientific knowledge and others for the best solution. Students should have chance to argue about science related to technological and societal issues. Students' argumentation becomes dominated by dichotomies like 'chances and problem', 'advantages and disadvantages', or uses and abuses'. Students have to select between alternatives of solution by systematically comparing as many relevant pro's and con's as possible. Then, students' ideas, designing, proposing system, or volition will be drawn or constructed.

(v) Socialization stage: The stage is designed to allow students to validate their values and scientific concepts for solutions during their sharing in society. Students need to do something as people who are a part of society by reporting their proposal for solving problem. Students might exhibit their solution in public. Or, students may communicate their products, science projects, ideas, designing, proposing system, or volition to the head of community, or share to social media and newspaper. Then, students need to report what they learned from the validation or sharing their proposal or product through socialization process.

Yuenyong (2006)'s STS approach in the area of decision-making focused on decision making, normative decisionmaking, and the process of decision-making (Yuenyong, 2013). For example, Luengam and Yuenyong (2009) enhanced Grade 7 students' normative decision-making in STS teaching and learning about global warming. This study reported students' normative decision making based on students' giving reasons about issues related to global warming. The aspects of normative decision-making were reported regarding to three dimensions including 1) the influence of global warming on technology and society; 2) the influence of societal values, culture, and society on global warming; and 3) the influence of technology on global warming. Anantasook and Yuenyong (2010) examined Grade 12 students' decisionmaking process in STS nuclear physics learning unit. They reported decision-making process as 'ISPED'. The ISPED stand for: I - identifying the issues; $\mathbf{S}$ - searching and selecting the information necessary for the decision-making processing; P - proposing potential solutions; E - evaluating the possible solution; and D - deciding the appropriate solution.

In order to provide personal relevance for chemistry constructivist learning environment, the local issues of chemistry issues related to technology and society should be raised in the class. Students, then, have chance to integrate scientific and other knowledge when they are moving on the process of decision making on those issues. This research is aimed at clarifying how Thai students' make decisions as regards societal issues of surface area and concentrated solutions as a factor in the rate of chemical reactions.

\section{Methodology}

The research regarded on interpretive paradigm in order to clarify phenomena of how students' make decisions as regards societal issues of surface area and concentrated solutions as a factor in the rate of chemical reactions. This research will describe the behavior of students' decision making on chemistry related on technological and societal issues. The student behavior was interpreted based on their school natural setting (Marriam, 1998; Cohen et al., 2000). This research aims to interpret students' decision making in societal issue of surface area and concentrated solutions as a factor in the rate of chemical reactions. The interpretation and writing research report concerning on trustworthiness.

\subsection{Participants}

The participants were 35 Grade 11 students in Ban Haed District ofKhonKaen Province, Thailand.

Table 1: Overview of the STS sub-unit of surface area and concentrated solutions as a factor in the rate of chemical reactions

\begin{tabular}{|l|l|l|}
\hline $\begin{array}{l}\text { Stages of Yuenyong (2006)'s STS } \\
\text { approach }\end{array}$ & Teaching activities \\
\hline (i) Identification of social issues & $\begin{array}{l}\text { Instruction will begin by posing issues related to scientific knowledge in society. The issues of } \\
\text { locked and rusty railways were raised in class as stipulated below: } \\
\text { - Show students a lock which is difficult to unlock. And, then, ask students how to unlock and } \\
\text { why it is difficult to unlock. (Students may mention about the rusty key or lock. } \\
\text { - Raise the question, what will happen, if the rails at Ban HaedRailway station gets rust? } \\
\text { (students may talk about how the problem of rusty railways can be solved; change the iron of } \\
\text { railway and railroad sleepers, and the budgets for finding the solutions) } \\
\text { - Ask students how we can protect the Ban Haed railway from rusting. }\end{array}$ \\
\hline (ii) Identification of potential & Students plan to solve the issues of locked and rusty railways and the possible solutions. \\
\hline
\end{tabular}




\begin{tabular}{|c|c|c|}
\hline solutions & $\begin{array}{l}\text { Students wrote down their questions about 'rust' on the worksheet } 2 \text {. } \\
\text { Then, students presented their own questions to the classroom in order to find some possible } \\
\text { ideas for the sake of investigation. }\end{array}$ & \\
\hline (iii) Need for knowledge & $\begin{array}{l}\text { This stage involves developing chemistry knowledge: the issues of locked and rusty railways } \\
\text { creates the need to know some chemistry content. Students were instructed to do the following } \\
\text { activities: } \\
\text { - Students watched the video clip of how chemical reactions are generated ( } 15 \text { minutes). Then, } \\
\text { students wrote down what they learned from the video and were dumbfounded about the story. } \\
\text { - Teachers collected students' questions and discussed about the questions in order to upgrade } \\
\text { students' knowledge about the aforementioned topic. } \\
\text { - Teacher asked students to do experiment about the rate of chemical reactions. Because the } \\
\text { video clip mentioned some relationships between the surface area, concentrated solution, and } \\
\text { rate of chemical reaction; and how we can explain the relationship. }\end{array}$ & \\
\hline (iv) Need for knowledge (continued) & $\begin{array}{l}\text { - Students did experiment about surface area and concentrated solutions as a factor in the rate } \\
\text { of chemical reaction. }\end{array}$ & \\
\hline (v) Decision-making & $\begin{array}{l}\text { This stage involves students in making a decision on how to use chemistry knowledge and } \\
\text { technology in order to protect Ban Haed railway from rusting. Students spent time to design } \\
\text { their projects. They decided to present new models of preventing railway from rusting, the } \\
\text { strategies to protect and use railway, or set strategies for Ban HaedRailway station to take care } \\
\text { of its rails. }\end{array}$ & 1 \\
\hline (vi) Socialization stage & $\begin{array}{l}\text { Socialization process will allow students to validate their values and chemistry concepts for } \\
\text { solutions during their sharing in society. Students presented their projects at Ban Haed } \\
\text { municipality. }\end{array}$ & Extra time \\
\hline
\end{tabular}

\subsection{Methods of Inquiry}

This research interprets students' decision making from a sub-unit of the factors in the rate of chemical reactions.It was one of four sub-units of factors in the rate of chemical reactions. The unit of factors in the rate of chemical reactions was taught through Yuenyong (2006)'s STS approach for 4 weeks. The unit consists of 4 sub-units: (i) surface area and concentrated solutions, (ii) catalysts, (iii) temperature, and (iv) inhibiter. Therefore, only $11^{\text {th }}$ Grade students' decision making in societal issue of surface area and concentrated solutions as a factor in the rate of chemical reaction has been clarified in this submission.

The STS sub-unit of surface area and concentrated solutions as a factor in the rate of chemical reaction has been highlighted as shown in Table One. Tools of interpretation includes: firstly, participant observation, secondly, individuals, groups, and informal interviews, thirdly, journal writings or personal summaries, and fourthly, students' tasks. Students' responds, dialogues, ideas, or conversation being arranged in to patterns in order to explain students' common themes of the normative decision making model. This common themecontainssix steps: (i) options (ii),criteria (iii) validity and clarify of information of each criterion, (iv) evaluation (v) choice, and (vi) review.

\section{Findings}

Students' ideas in developing a solution for the protection of Ban Haed railway could be interpreted by their ability of decision making model as provided in Table Two. The finding revealed that some students had six steps of decision making for their projects, as follows: i) options, ii) criteria, iii) clarifying of information of each criterion, iv) evaluating the advantages and disadvantages of each alternative, v) choice analysis, and vi) selection of the best alternative.

According to Table Two, it indicates that the STS sub-unit of surface area and concentrated solutions as a factor in the rate of chemical reactions allows students to develop their model of decision making. Their model could be classified in to six steps of decision making: i) options, ii) criteria, iii) clarifying of information of each criterion, iv) evaluating the advantages and disadvantages of each alternative, v) choice analysis, and vi) selection of the best alternative.

The first step is options; Students could list or identify the possible alternative ways of action in considering the problem or issue. Students, for example, identified the problem of iron oxidization and found it to be a solution to make rails last long, when they were engaged in the STS stage of identification of social issues. This could be seen instudents'idea (S3 and S6) which mentioned flooding, cause of rusty irons, and extending life of railway irons.

Secondly, making criteria: students could develop suitable criteria to use in comparing alternative ways of preventing Ban Haed railway iron from rusting. They identified the aim of finding solutions in order to set the criteria for finding alternative ways (S3, and S4)This could be mentioned that they generated the criteria to evaluate the possible alternatives.

Thirdly, they clarified information of each criterion that they proposed. They explained alternative ways of how to 
reach the aims that were proposed in the first step. They proposed various alternative ways such as covering iron through coloring, oiling, or plastics, and also using other metals to make the railway long lasting.

Fourthly, after evaluating the alternatives, the advantages and disadvantages of each alternative were explained before decision making. According to Table Two, students considered renewing the railway and quality of stainless steel as an advantage. And as a disadvantage, it was referred to as a waste of money and a high cost of energy.

Furthermore, they ranked the alternative ways by balancing between advantages and disadvantages. This could be mentioned by analyzing the choices.

Finally, they selected one alternative as the best solution which concerned what they could be able to doto relate to their real life.

Table 2: Students' ability of decision making as concerns rusty irons at Ban Haed railway.

\begin{tabular}{|c|c|}
\hline Steps of decision making & Students' statements that represents their consideration in each step of decision making \\
\hline Options & $\begin{array}{l}\text { Students could identify problems as, the issue of flooding. And they list the possible } \\
\text { considerations or issues. For example, S3 and S6 students clarified their ideas in the STS } \\
\text { stage of identification of social issues. } \\
\text { "Iron will become rusty. How can we provide some solutions to prevent the iron of the railway } \\
\text { from rusting so as to increase its lifespan?" (S3) } \\
\text { "Flooding is one of the causes of railway rusting. Brown and black irons are rusty irons." (S6) }\end{array}$ \\
\hline Criteria & $\begin{array}{l}\text { Students identified the aim of finding solutions in order to set the criteria for finding alternative } \\
\text { ways as follows: } \\
\text { "Decrease the rate of iron rusting and extension of its lifespan." (S4) } \\
\text { "Strong structure of railway and extension of its lifespan" (S3) } \\
\text { "Upgrade the Ban Haed railway iron to meet Thailand standard of industrial products"(S6) }\end{array}$ \\
\hline Clarifying of information of each criterion & $\begin{array}{l}\text { Students clarified the information known about possible alternatives. They also provided } \\
\text { alternative ways of how to reach the aims of their proposed ideas. Below are their alternative } \\
\text { ways: } \\
\text { (i) Color the iron (ii) Make the oil cover the iron (iii) Cover the iron with plastics" (S34) } \\
\text { (i) Color the iron to cover the iron from air and water. (ii) Make the rails from Stainless steel or } \\
\text { corrosion resistant steel. (iii) Make the railway under high temperature or static electricity" (S3) }\end{array}$ \\
\hline $\begin{array}{l}\text { Evaluate the advantages and } \\
\text { disadvantages of each alternative }\end{array}$ & $\begin{array}{l}\text { Students could evaluate the advantages and disadvantages of each alternative in order to find } \\
\text { some ideas for making decisions. Students idea in S3 is an example: } \\
\text { "An advantage of the first alternative way to cover iron with coloring is to renew the railway iron } \\
\text { and shifting the quality of iron to the next level. As a disadvantage, It's a waste of time and } \\
\text { money. } \\
\text { As an advantage of the second alternative, using of stainless steel is to make the railway } \\
\text { not to rust. However, as a disadvantage, It a waste of money and high cost of energy. } \\
\text { The advantage of third alternative, iron made with high temperature or static electricity, is } \\
\text { product of high standard of iron. It is disadvantageous because of high cost of electricity" (S3) }\end{array}$ \\
\hline Choice Analysis & $\begin{array}{l}\text { Students could try to analyze the choice for decision. They ranked the alternative ways based } \\
\text { on their reasons. Students idea in S3 is an example: } \\
\text { "I will rank the alternative way as } 2 \rightarrow 3 \rightarrow 1 \text { because I am much concern with the high } \\
\text { standard of iron as provided by Thailand standard of industrial products" (S3) }\end{array}$ \\
\hline Selection of the best alternative & $\begin{array}{l}\text { Students selected an alternative after they analyzed their choices. The best alternative is the } \\
\text { one that appropriate for their context and daily life. S3 student idea is an example: } \\
\text { "I selected the alternative ' } 1 \text { ' because I can find the material in everyday life. It also can protect } \\
\text { the railway iron from rusting." (S3) }\end{array}$ \\
\hline
\end{tabular}

\section{Conclusion}

In sum, science teaching through STS approach gives students a chance to learn not only scientific knowledge but also developing the model of decision making. Their model could be classified in six steps of decision making: i) options, ii) criteria, iii) classification of information into each criterion, iv) evaluating the advantages and disadvantages of each alternative, v) choice analysis, and vi) selection of the best alternative. It could be mentioned that students could develop their ability of decision making while they learned in the STS sub-unit of surface area and concentrated solutions as a factor in the rate of chemical reactions. The findings suggested that students could learn concept of science, technology, and other knowledge from their local community. This learning activity may enhance students to integrate many kinds of knowledge to gain their scientific literacy (Seattha, Yuenyong, and Art-in, 2015; Yuenyong and Narjaikaew, 2009). The STS unit in local or/and global issues should be introduced widely to teachers. Thisresearch, therefore, has the 
knowledge and capability if applied, of ensuring higher performance of Thai students' science know how on PISA test.

\section{References}

Aikenhead, G. (1994). What is STS science teaching? In Solomon, J. and Aikenhead, G. (Eds.).(pp.169 186).STS Education: International Perspective on Reform. New York, USA: Teachers College Press, Columbia University.

Anantasook, S. \& Yuenyong, C. (2010) Grade 12 Students' Decision Making Process in Physics Learning about Nuclear Physics through Science Technology and Society Approach. Paper presented at the 2nd East Asian International Conference on Teacher Education Research, Hong Kong Institute of Education, Hong Kong, 15-17 December.

Bingle, W. H. and Gaskell, P. J. (1994).Scientific literacy for decision making and the social construction of knowledge. Science Education,78(2), 185201.

Cohen, L., Manion, L. and Morrison, K. (2000).Research Methods in Education.London, UK: RoutledgeFalmer.

Institute for the Promotion of Teaching Science and Technology (IPST). (2002). The Manual of Content of Science Learning. Bangkok, Thailand: Curusaphaladphoa.

Kortland, K. (1992). Environmental Education: Sustainable development and decision-making. In Yager, R. E. (Ed.), The Status of STS reform efforts around the world: ICASE Yearbook 1992. Peterfield, UK: International Council of Association for Science Education. $32-39$.

Kortland, K. (1995). Decision-making on Science-related Social Issues: The Case of Garbage in Physical Science - A Problem-posing Approach. In Westford, G., Osborne, J., and Scott, P. (Eds.).Research in Science Education in Europe: Current Issues and Themes. London, UK: The Falmer Press, $115-125$.

Kortland, K. (1996). An STS Case Study about Students' Decision Making on the Waste Issue. Science Education. 80(6): 673 - 689.

Luengam, P. \& Yuenyong, C. (2009) Grade 7 Students' Normative Decision Making in Science Learning about Global Warming through a Science Technology and Society (STS) approach. Paper presented at the 40th Annual Conference of the Australasian Science Education Research Association (ASERA) 2009, Geelong, Victoria, Australia, 1-4 July.

Merriam, S. B. (1998). Qualitative research and case study applications in education. SanFrancisco: Jossey-Bass.

Ratcliffe, M. (1995).Adolescent decision-making, by individuals and groups, about science-related societal issues.In Westford, G., Osborne, J., and Scott, P. (Eds.).(pp. 126 140).Research in Science Education in Europe: Current Issues and Themes. London, UK: The Falmer Press

Seattha, P., Yuenyong, C. and Art-in, S. (2015). Developing STS Circular Motion Unit for Providing Students' Perception of the Relationship between Science Technology Engineering and Mathematics. Mediterranean Journal of Social Sciences, 6(3s1): 268 -275 .

Yuenyong, C.: (2006),. Teaching and Learning about Energy : Using STS approach. Bangkok, Thailand : Thesis of Doctoral Degree in Science Education, Kasetsart University.

Yuenyong, C. (2012). Thai students' decision making about energy issues: the influence of local values. . Procedia - Social and Behavioral Sciences. 46: $5045-5057$

Yuenyong, C. (2013). Enhancing Scientific Literacy in Thailand. Global Studies of Childhood, 3(1): 86 - 98

Yuenyong, C. and Narjaikaew, P. (2009).Scientific Literacy and Thailand Science Education.International Journal of Environmental and Science Education. 4(3): 335349. 